This item was submitted to Loughborough's Research Repository by the author.

Items in Figshare are protected by copyright, with all rights reserved, unless otherwise indicated.

\title{
What will designers do when everyone can be a designer?
}

PLEASE CITE THE PUBLISHED VERSION

https://www.routledge.com/Design-for-Personalisation/Kuksa-Fisher/p/book/9781472457394

\section{PUBLISHER}

(c) Taylor and Francis (Routledge)

\section{VERSION}

AM (Accepted Manuscript)

\section{PUBLISHER STATEMENT}

This work is made available according to the conditions of the Creative Commons Attribution-NonCommercialNoDerivatives 4.0 International (CC BY-NC-ND 4.0) licence. Full details of this licence are available at: https://creativecommons.org/licenses/by-nc-nd/4.0/

\section{LICENCE}

CC BY-NC-ND 4.0

\section{REPOSITORY RECORD}

Sinclair, Matthew. 2019. "What Will Designers Do When Everyone Can Be a Designer?”. figshare. https://hdl.handle.net/2134/25838. 


\title{
What Will Designers Do when Everyone can be a Designer?
}

\author{
(2017, appearing in Kuksa, I. and Fisher, T. (eds), Design for Personalisation, pp. 91-112, \\ Farnham, UK: Ashgate. ISBN: 978-1-4724-5739-4)
}

\section{INTRODUCTION}

"We, the people, the untrained majority, are the future of design. We have the tools and we will be the masters of our personal environments... We're not dumb consumers, we're creative consumers... We won't buy anything that isn't uniquely specified by ourselves."

When Justin McGuirk wrote the above in 2009, a contemporary discussion about the ability of non-designers to engage in design and personalisation activities was already well established. Originating in theories of Participatory Design and Co-Design, the debate had been re-energised by the possibilities emerging from new approaches to manufacturing provided by digital fabrication technologies such as laser cutting and additive manufacturing (to become known more popularly as 3D Printing). Often referred to under the umbrella term of the 'Maker Movement', this stream of activity emerged among enthusiasts and hobbyists empowered by access to these increasingly low cost technologies. The users of 3D Printers by companies such as Makerbot and Ultimaker, and electronics and computing platforms such as Arduino and Raspberry Pi, provided some of the most visible examples of the open source community ethic which characterised the movement.

The proposition that design is an activity in which anyone can take part is not one which attracts consensus easily. Whereas writers such as Norman (2004: p.224) have argued that "We are all designers," and that deciding where to put your coffee cup and book is an act of design, practitioners such as Jonathan Ive (2009) have countered that "It sounds egalitarian to say in future people should design their own stuff, but that's the designer's job - to solve problems." Mass Customisation literature commonly employs terms such as "user-designer" (e.g. Franke and Piller, 2004) as well as assertions that "The professional designer is replaced by the user" (Randall et al, 2003), causing designers to question the writers' understanding of the practise of design. Others have attempted simply to shut down the argument, insisting, in the words of author Andrew Keen, that "Consumers consume; designers design. End of Story," (Duffy and Keen, 2006). These binary positions, which might be summarised as "everyone is a designer" or "only professional designers can design", have shed little light on 
the potential of digital fabrication technologies, or the new design processes which have emerged as a result. Fischer (2002) has previously argued against the over-simplification of these positions when suggesting that 'consumer' and 'designer' are not binary choices, and that a continuum exists between the two. Most importantly however, such arguments have largely been ignored by those involved in the Maker Movement, who have gone ahead and designed and manufactured products whether designers and design theorists like it or not. In so doing they have created a multitude of products: objects which function poorly and objects which function perfectly; objects which dismay and objects which delight; objects of crassness and objects of beauty; in short they have created things which elicit a similar range of reactions to those conceived by professional designers. Thus the question "What will designers do when everyone can be a designer?" has become ever more pertinent.

In this chapter, the author writes from the position that there is no fundamental difference between the design practised by professionals and that undertaken by amateurs. In evaluating design, we should make judgements based on the merits of the outcome, rather than the status of those involved. Nonetheless, those who have been trained and who practise design professionally will possess expertise in areas which non-professionals do not. For some advocates of user involvement in design, greater engagement is always a goal to aim for. However one of the key differentiators of the new approaches to design discussed below is the degree to which they offer users the freedom to design their own products. For many amateur designers, the ability to utilise their own expertise (in a particular field, for a specific purpose, or simply in the understanding of what they individually require) is enabled by the expertise of professionals. Thus in many instances, it is the constraints placed on the user which provide the opportunity for involvement in design.

\section{CONSUMER INVOLVEMENT IN INDUSTRIAL DESIGN}

The Maker Movement is a multi-faceted phenomenon, accepting of participants with interests as diverse as electronics, robotics, biology and programming, to weaving, marquetry and even performance art. However it is the use of digital technologies, both the manufacturing hardware and the software which drives it, which encroaches most deeply into territory conventionally considered that of the designer. Further challenges come to designers from industrial manufacture, through the development of new approaches to 
design such as Mass Customisation and Crowd Sourcing. In order to begin answering the question posed in the title of this chapter, it is therefore necessary to understand what is meant by design, and in particular industrial design, which traditionally poses itself as the means by which industry conceives of consumer products.

The difficulty of ascertaining what industrial design actually is was recognised by Ralph Caplan (1969: p.1) in his introduction to Design In America, in what remains one of the most insightful and relevant essays on the practice of industrial design despite being written close to fifty years ago:

"What is industrial design? It was never an easy question to begin with, and it has not, through the years, become any easier. Essentially, industrial design determines the form of objects that are to be mass-produced by machines rather than crafted by hand. But while this has long been an essential definition, it is no longer sufficiently comprehensive, if indeed it ever was... First of all, the designs are not necessarily mass produced... Nor is the work necessarily done for industry."

Ultimately Caplan fails, or refuses, to define exactly what industrial design is, for reasons which appear remarkably prescient of the issues raised by digital manufacturing. Others have been less wary, typically viewing the end user as an external influence on the solutions that designers arrive at, or as part of a target market (e.g., IDSA, 2014). Some of the most widely used definitions are therefore unable to account for the possibility of consumers who design and/or manufacture their own products. In addition, definitions of industrial design which refer to 'mass manufacture' or 'volume production' (e.g. McDermott, 2007; Design Council, 2010) have increasingly proved inadequate at describing design for digital manufacture, in which low volume or even unique products are the outcome.

Definitions of industrial design based on an observation of process, rather than a description of service, overcome this problem somewhat. Fiell and Fiell (2003) for example, describe industrial design as

"the conception and planning of products for multiple reproduction - [it] is a creative and inventive process concerned with the synthesis of such instrumental factors as engineering, technology, materials and aesthetics into machine-producible solutions that balance all user needs and desires within technical and social constraints." 
This definition is not without weaknesses: the term 'multiple reproduction' is problematic (though not to the same degree as "mass produced"), although it could be argued that a consumer-designed product is potentially reproducible, even if only one is actually made. Importantly though, by listing the tasks typically carried out by the industrial designer, the definition allows for the possibility that a consumer undertaking some of the tasks (rather than all) is acting as a designer.

In a typical model of the Industrial Design process (Figure 1), the early stages of a project will involve the generation of multiple concepts for how the product might be resolved. During these stages the designer will be widening the possibilities of what the actual product might be. However, in a typical product development project, this widening might account for less than $10 \%$ of the total work involved in the process of designing a manufacturable and saleable product, and rarely more than $25 \%$. The remainder will involve consolidating and filtering, rejecting unsuitable designs and refining more suitable ones, prototyping and then further refining, and repeating stages where necessary, with the ultimate goal of arriving at the smallest possible number of solutions, which can then be reproduced identically in high volume. So ingrained is this process that many industrial designers (as previous definitions illustrate), define what they do as design for mass manufacture. They believe that industrial design is about designing a single product for multiple users, and they propose that this is what distinguishes design from craft (Risatti, 2006; Walker, 1989: pp.38-39). Increasingly, developments in manufacturing processes are demonstrating that this belief is wrong.
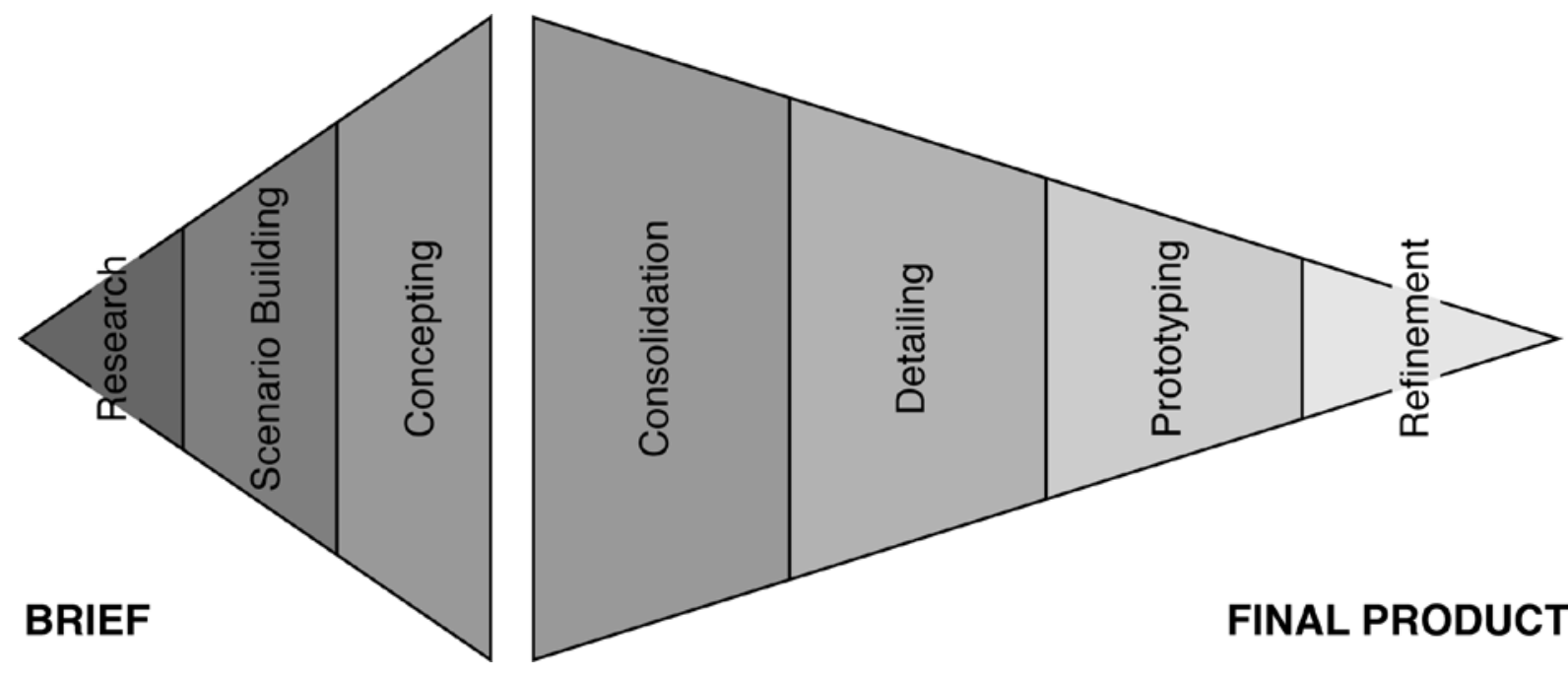

Figure 1. Industrial Design Process Model. 
The Industrial Design process described above is a result of the profession's service of industrial manufacturing. One of the common features of mass production is that the means of production require substantial initial investment, however once in place, the cost of manufacturing a single part or product (relative to the initial investment) is negligible. It is therefore a basic principle of mass production that as the number of parts produced increases, the cost of production of each individual part decreases. This inevitably leads to uniformity, as even small design changes require significant reinvestment in tooling, and since products must be produced in high volume, a product's aesthetics must appeal to many, not just a few. However, without the need for significant investment in mass production tooling (Mansour and Hague, 2003), digital fabrication offers the theoretical possibility that every concept can make it through to production. As manufacturing changes, from a paradigm of mass production to one in which digital manufacturing makes unique, personalised production possible, industrial design will also be forced to change. A number of researchers have proposed that such changes represent the possibility of a future in which designer-consumer relationships more closely resemble those of pre-industrial artisanship (Campbell et al, 2003; Bonanni et al, 2008; Aldersey-Williams, 2011). This vision does not require that all consumers engage in the design and manufacture of products - "it's not that everyone will, but that anyone can," as Nilofer Merchant (2013) puts it. Nor does it require that designers create unique designs for every individual consumer. Instead, if they are to fully exploit the potential offered by digital fabrication technologies, they must begin to become what Tonkinwise (2004) describes as "designers capable of designing things that are not finished." They will be designers of products which require unique decisions and inputs from consumers, and which are deliberately designed to be incomplete without the consumers' input.

It is in this type of scenario that the question of the user acting as, or replacing, the designer starts to be resolved. When using the NikeID configurator for instance, a consumer choosing colours to create a personalised shoe is clearly not performing all of the tasks that a designer working for Nike does. But equally clearly, the consumer is performing one of the tasks (colour selection) which would have been the job of the designer if NikelD did not exist. Therefore, whilst it is not true to say that the consumer is able to replace the designer, it is undeniable that in this context the consumer possesses the expertise to do what, in other circumstances, would be described as design. 


\section{AMATEUR AND PROFESSIONAL EXPERTISE}

The IDSA definition mentioned previously states that industrial design is

"the professional service of creating and developing concepts and specifications that optimize the function, value and appearance of products and systems for the mutual benefit of both user and manufacturer." (IDSA, op.cit.).

Unsurprisingly for a body whose membership consists of those who work in the industry, the emphasis on professional service implies those not employed as designers should not describe what they do as industrial design. The exclusive nature of such a definition points to a key differentiator between those who engage in design activities: the expertise of the professional versus that of the amateur.

Much of the literature dealing with personalisation and the involvement of the consumer in the design process has concentrated on the possibility of changing the product's appearance (e.g. Mugge et al, 2009; Bernabei and Power, 2013). The purpose of the traditional design process is not just to impose a uniform visual aesthetic however, it also refines or rejects on the basis of ergonomics, durability, safety, reliability, integration with other products and systems, cost, and so on. These are all areas in which the designer's training and expertise is likely to remain the best tool to resolve the conflicting demands of a commercial product brief. However, it is in the identification of those areas where the amateur's expertise is superior to that of the professional, that we can begin to identify how the role of the designer might change in future.

In the past, one of the key advantages of the professional designer - what allowed them to engage in design to a higher level than the amateur - was their access to the means of production. This advantage no longer exists. Online services mean that anyone can access digital manufacturing technologies equal in sophistication to those that the professional designer can use. Nowadays the main difference between professional and amateur is that the professional designer designs what someone else (the user) wants, and which someone else (the client) specifies. In contrast, and what is especially interesting about the work done within the Maker community, is the fact that so much of it is created for personal use. Obviously many designs are shared, re-used and modified, but this represents a very 
different scenario to that of the professional designer's task of trying to take a 'target market' into account from the beginning of a project. That the user and the designer are the same person is what differentiates amateur expertise from professional.

Within the field of industrial design, strategies such as user-centred design and co-design are common-place methods for the integration of user needs into the design process (Sanders and Stappers, 2008). The implementation of such strategies has been criticised as often misguided or ineffectual (Ulwick, 2002; Goodman-Deane et al, 2010; Steen, 2011), leading to incremental improvements rather than significant new ideas. Nonetheless it is now commonplace for brands to talk of the extent to which they are customer-driven (Binder et al, 2008). Conventional wisdom holds that products which emerge from a focus on the needs of users better address those needs and thus lead to greater consumer satisfaction and, ultimately, greater profitability (Vredenburg et al, 2002; Design Council, 2008). But conventional wisdom rarely questions the causes of the need to be user-oriented, or why professional design expertise must spend so much effort attempting to understand the user. The reason is not that understanding the user is inherent to the nature of design, rather it is because failing to understand the user is inherent to mass production. As Aldersey Williams (op. cit.) observes, user-centred design is intended "to ensure not the best outcome for one consumer but the least worst outcome for all consumers, and thus the best result for the manufacturing company." It is the nature of mass production that demands designers create one single product that appeals to thousands or even millions of users, which in turn means trying to uncover the problems or characteristics that all users share. This tendency was previously alluded to by Redström (2008), who observed that the conventional need to understand the user becomes confused, if not contradictory, in situations where users themselves participate in acts of personalisation and design. Thus in responding to the requirement of mass production to conduct user-centred design professional designers reveal a significant flaw in their expertise - no matter how well they understand the user, they will not understand him/her as well as the amateur who is designing for themselves. 


\section{NEW APPROACHES TO INDUSTRIAL DESIGN}

In an idealised user-centred design process, the brief will be written in the full understanding of what the user believes to be important. The designer will work to, or perhaps challenge, the brief based on observations and discussions with consumers, who will be invited to comment on concepts and designs (Black, 2007). Co-Design extends the scope of user involvement by encompassing both "designers and people not trained in design working together in the design development process" (Sanders and Stappers, op.cit.). However in both methods, the designer remains in a position of power - ultimately the degree to which the user's expertise is followed or ignored is the decision of the designer. This is a situation which a number of new approaches to design have challenged.

Sinclair and Campbell (2014) present a classification of Consumer Involvement in New Product Development (NPD), which compares these new approaches to more conventional methods (Figure 2). In the model, the extent to which design processes facilitate user engagement in design is mapped according to the degree to which the designer is committed to the involvement of the user.

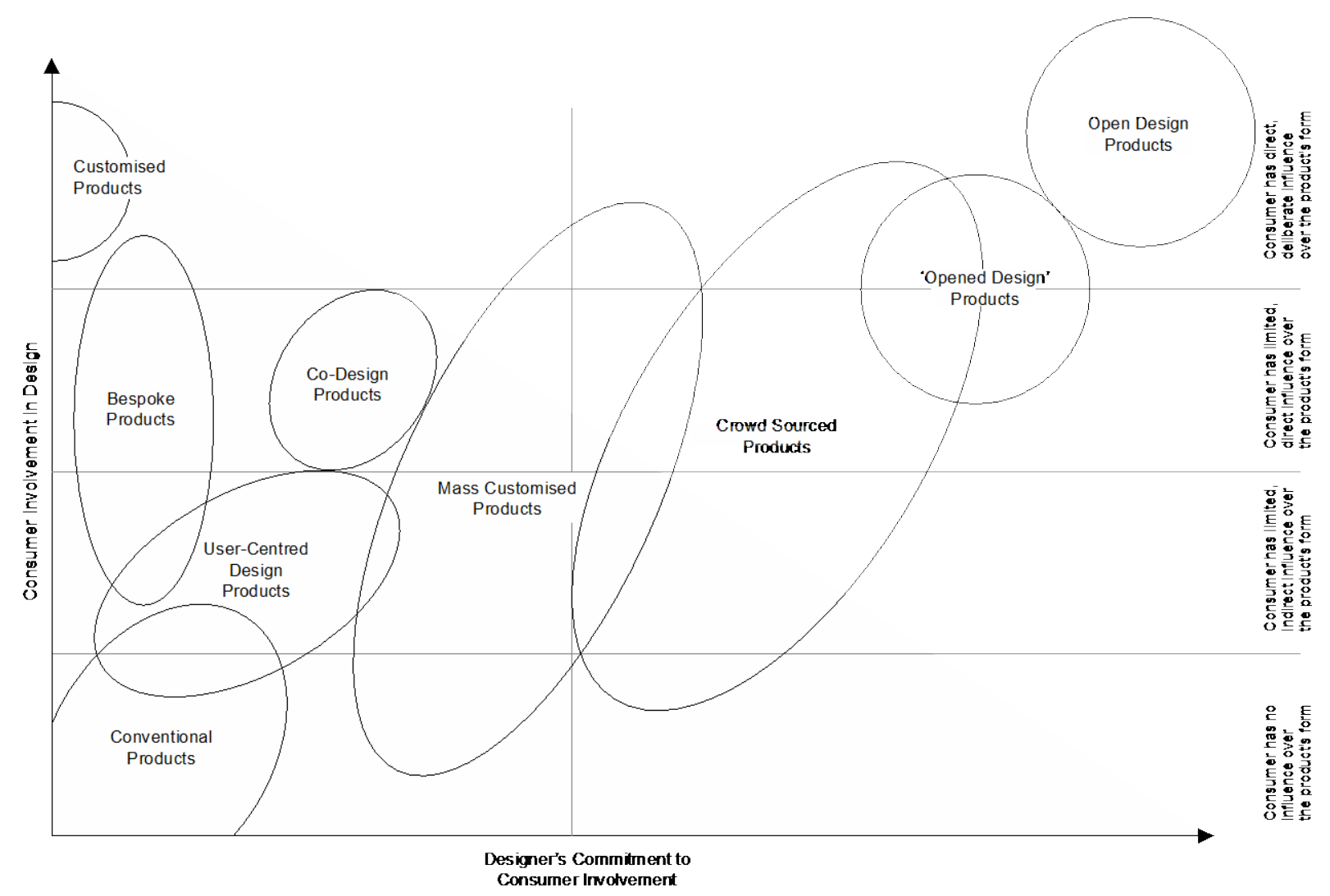

Figure 2. A classification of consumer involvement in New Product Development 
The designer's commitment to consumer involvement in NPD refers to the degree of autonomy enjoyed by the user in the personalisation or design of products. Within Figure 2, moving along the horizontal axis from left to right shows an increasing opportunity for the user to affect decisions about a product's creation. On the left of the diagram, in more conventional design processes such as user-centred design and co-design, the designer employs professional expertise in order to act as an interpreter of user needs and wishes. This "executive approach" (Oudshoorn and Pinch, 2003: p.7) "assumes a specific type of power relations... in which designers are represented as powerful and users as disempowered relative to the experts." However, as the degree of user autonomy increases, a 'tipping point' is reached where these traditionally unchallenged power relationships are inverted. Products that users customise (examples of which include cars, PC's and even coffee machines) are modified with considerable freedom with respect to the product's functionality, appearance and the tools and methods used to customise them. Nonetheless, despite their very high degree of consumer involvement, such modification takes place without the designer's permission; customised products therefore exhibit a very low degree of designer's commitment. In contrast Open Design products are deliberately provided in formats that are easy to modify, and ideally with instructions or tutorials as to how modification can be carried out. The new approaches to design therefore require that the designer no longer acts as an interpreter of needs, but instead as a facilitator (Siu, 2003) of the consumer's desire to personalise products to better address his/her own requirements. Clearly, in such circumstances not only has the nature of the designer's relationship with the user changed, but also the way in which a designer's own work is conventionally understood. Designers working within processes on the right of the diagram will have thus transferred considerable responsibility for a product's final manifestation, relying instead on the expertise of the user to create a fully resolved product.

As well as user involvement in NPD as a result of the designer's commitment, Sinclair and Campbell's (op. cit) classification also illustrates the effectiveness of user involvement with regard to the creation of unique products. Existing models of NPD (e.g. Ulrich and Eppinger, 1995; Perks et al, 2005) divide the process into phases, summarised as Conception, Specification, Design and Manufacture. Depending on the design method involved, a user may exert influence in any of these phases, thus approaches to design in which a user is involved in these phases naturally provide him/her with more effective means of influencing 
the final, manufactured product. The vertical axis of consumer involvement is therefore divided into four regions corresponding to an increasing influence over the product's form, whether for aesthetic, ergonomic or functional purposes. The first region represents the lowest level of consumer involvement, and corresponds to most conventional models of design within NPD. In this region consumers have no possibility of exerting direct influence over a product's design. At the second level the consumer may exercise indirect influence over product form. In a user-centred design process this influence is limited to interactions with the product's designer, who uses their professional expertise to judge the extent to which those interactions should determine the object's design. Alternatively, as part of a mass customisation process, influence over a product's form (usually its size) will indirectly result from requirements of fit. It is at the third level of involvement that the consumer begins to directly influence product form. In the case of a co-design or bespoke design process, this will again be mediated through the designer's expertise, but in a mass customisation process the designer will have no veto on the final outcome: instead the user will be limited by the number and type of components available. It is only at the fourth level of user involvement that opportunities for influence over a product's three-dimensional form are manifested. At this level user influence is both deliberate and unmediated: form can be modified and defined without the approval of the designer and without the constraints imposed by predetermined modules or components. This is not to suggest that no constraints exist - a consumer-designed object must take account of materials and production realities in the same way that a professionally designed object must. In fact, the ability of the designer to provide the user with creative freedom, within pre-existing constraints, will in future be one of the criteria which distinguish professional expertise from amateur, as discussed at the conclusion of this chapter.

\section{MASS CUSTOMISATION}

The approaches in which designers facilitate the most effective engagement in NPD, Mass Customisation, Crowd Sourcing, Opened Design and Open Design, appear to the right of the diagram. Mass Customised products are those whose design and specification are modified with direct consumer input, usually through online configuration tools (von Hippel and Katz, 2002; Piller, 2005; Franke et. al; 2010). The concept was first described by Stan Davis (1987), 
who envisaged a future where the concept of mass production for mass markets was replaced by one in which every customer could have goods and services tailored to their individual needs and wishes. This concept was substantially elaborated by Pine (1993) in 'Mass Customization: The New Frontier in Business Competition', and later defined by Kaplan and Haenlein (2006) as "a strategy that creates value by some form of companycustomer interaction at the fabrication/assembly stage of the operations level to create customized products with production cost and monetary price similar to those of massproduced products." Typically this will involve the selection of features from a predetermined menu, to create a personalised product that more accurately meets the consumer's needs than a standard offering. NikeID is one of the best known and most successful examples, reportedly generating more than $\$ 100$ million in sales in 2009 (Wong, 2010). In recent years however, a new class of mass customisation toolkit has begun to appear; these configurators do not rely on the choice or arrangement of modules, but instead allow the precise manipulation of a product's form. This 'fine grain' control relies on two factors: (1) a parametric design interface (Hermans and Stolterman, 2012) as part of the toolkit; and (2) the use of digital fabrication technologies, in particular 3D Printing, to produce the user-customised part.

An example of this new class of toolkit is the Cell Cycle configurator by Nervous System, a design studio creating jewellery and housewares which specialises in the use of generative design - software algorithms that create forms based on both user input and the interaction of the form with itself (Rahim, 2009). Generative design typically produces naturalistic forms, a fact reflected in names given to some Nervous System products: Algae, Ammonite, Dendrite and Xylem, for example. Cell Cycle enables users to create jewellery items such as rings and bracelets via an on-screen model, which can be rotated and viewed from different angles. On opening the configurator, the user is presented with a menu divided into three main operations. The first operation, presented in the menu to the left of the screen, allows the user to specify the type of product, the number of holes (cells), the edge style and whether the item has one or two layers. The second operation at the bottom of the screen provides fine grain control, allowing the product's profile to be twisted or 'morphed, and cells to be joined or divided. Finally the toolkit provides a choice of materials including laser sintered nylon or precious metals, and the displayed price is continually updated according to the user's design decisions. By allowing the user control over certain parameters pre- 
determined by the designer, and by updating the image of the model as the user manipulates its form, a significant degree of control over the product's final design is transferred to the user. Nonetheless, the Cell Cycle configurator exhibits a very carefully considered solution space, and it is difficult to imagine a product designed within the system that would not display a strong sense of the designer's intended aesthetic. In addition, and crucial to the success of the toolkit, the limits set within it ensure that the consumer designed product is manufacturable - for example the minimum material thickness for a piece manufactured in silver is $0.9 \mathrm{~mm}$, but this specification automatically updates to $1.2 \mathrm{~mm}$ if nylon is selected instead. As such, Cell Cycle can be considered an early example of the potential for designers to enable user expertise in the final design of products.

\section{CROWDSOURCING}

Crowdsourced products are those whose definition, specification and design occur with multiple direct consumer inputs. Kleeman, Voß and Rieder (2008) identify seven types of crowdsourcing, of which two - participation of consumers in product development and configuration, and product design - are relevant to this discussion. A crowdsourcing exercise will begin with an 'open call' for the submission of solutions to a problem (Howe, 2006a). Submitted solutions will then be considered by the 'crowd' with the aim of generating consensus around a popular solution which will be further developed for manufacture (Howe, 2006b). Crowdsourcing has attracted considerable attention within the field of Graphic Design, with many designers opposing a model which they see as devaluing their work (Howe, 2009) and organisations such as the American Institute for Graphic Arts (AIGA) taking positions which discourage members from engaging in the practice. However tangible, manufactured goods often require significantly greater interaction between designers and production engineers than graphic design projects, and so crowdsourcing within NPD is a much rarer phenomenon. Where it does occur, projects can exhibit a number of similarities to co-design, in that the user-designer will be invited to collaborate with an in-house team of product developers. Importantly however, in a crowdsourced project the design concept will have originated from the consumer alone, whereas in a co-design exercise it will more likely have been conceived by a designer working with the consumer. 
Perhaps the best known example of crowdsourced NPD is the Rally Fighter by Local Motors. Founded in 2007, Local Motors utilises crowdsourcing as a way of generating, selecting and developing designs for low production volume cars, which are then assembled (by their owners) in micro-factories under the supervision of Local Motors engineers. The first commercially available vehicle, the Rally Fighter, was conceived by Sangho Kim, a student at Art Center College of Design in California, whose design was judged (by other members of the Local Motors 'crowd') to be the best entrant to a competition to design an off-road (but street-legal) vehicle. Kim's design was then developed in response to both engineering constraints and feedback from the crowd. At the same time other members competed and submitted designs for elements of the car, for example the interior was designed by Mihai Panaitescu, a Romanian designer; side vents were designed by Laurent Raphael from Switzerland; and new graphic treatments were developed by Derek Salgado from Mexico (Rogers, 2010). Performance and safety-critical elements such as the chassis, engine and transmission were designed and sourced by Local Motors engineers (Anderson, 2010). Thus a collaborative model of crowdsourcing allowed the expertise of interested users to select a design, influence the way the design was developed, and fed into the functional specification, whilst at the same time utilising the professional expertise of automotive design engineers to ensure the vehicle functioned reliably and conformed to legal and regulatory requirements. In so doing the Rally Fighter was designed and manufactured five times faster than the industry standard (Rogers, op.cit). The vehicle, as a product that resulted from a crowdsourced design process, is a single design, much like that which would result from a traditional design process. However Local Motors also provides files for many of the car's parts, which can be freely downloaded and used to modify or improve the design: the Rally Fighter therefore also contains some of the characteristics of further new design approaches.

\section{OPEN DESIGN}

Open Design is an approach, closely related to Open Source, defined as "the free revealing of information on a new design with the intention of collaborative development of a single design or a limited number of related designs for market or nonmarket exploitation'" (Raasch, Herstatt and Balka, 2009). It has recently received significant attention following the publication of Open Design Now (van Abel et al, 2011), a collection of essays 
documenting the history, practise and future direction of open design. Katz (2011: p. 63) characterises open design as follows:

"A design is an open design if it bears four freedoms. One: The freedom to use the design, including making items based on it, for any purpose. Two: The freedom to study how the design works, and change it to make it do what you wish. Three: The freedom to redistribute copies of the design so you can help your neighbour. Four: The freedom to distribute copies of your modified versions of the design to others so the whole community can benefit from your changes. Access to the design documents is a precondition for these freedoms."

Open design products are those whose IP rights have been relaxed by the owner so that the consumer is free to modify all aspects of the product, from concept and specification through to design and manufacture. Subsequent IP rights will be determined by the terms of the licence under which the design is made available: whilst some impose no restrictions, others require that derivative works must be offered under the same terms (see for example the 'Attribution-Share-Alike' licence from Creative Commons). A product which has gained notoriety in recent years, as an example of the potentially far-reaching consequences of openly sharing designs, is the 3D printed Liberator gun, manufactured by Defense Distributed, and also referred to as the 'Wikiweapon'.

The passions generated by the issue of gun control and the rights of American citizens as a result of the $2^{\text {nd }}$ Amendment $^{1}$, means that it has often been difficult to separate the arguments surrounding the Liberator project from what it demonstrates about open design and digital fabrication. Even before the gun was first manufactured, the project aroused controversy when it was taken off the crowdfunding site Indiegogo (for violating the terms of service), an act quickly followed by Stratasys (the manufacturer of the 3D printer which Defense Distributed was leasing), which repossessed its machine (Defense Distributed, 2014). Nonetheless Cody Wilson, co-founder of Defense Distributed, denies that the company is trying to make a 2nd Amendment argument, instead insisting that "The basic idea is to take a technology, play futurist, and surprise people" (Dillow, 2012).

\footnotetext{
1 The Second Amendment of the United States Constitution (the so-called 'Right to Bear Arms') reads: "A well regulated Militia, being necessary to the security of a free State, the right of the people to keep and bear Arms, shall not be infringed."
} 
In terms of what the Liberator reveals about the future of design and its relationship to digital fabrication, the project has three lessons. Firstly, the argument that design in the fullest sense of the word cannot be practised by non-professionals is shown to be false. Wilson is not a designer or an engineer (he studied law at the University of Texas), but in creating the Liberator he was able to act as both. The design of the Liberator is far from a simple translation of an existing design - it uses two spiral springs which cock the trigger spring into position, a removable barrel and a body capable of withstanding the forces generated by the exploding round, all made from laser sintered plastic. Numerous prototypes were tested and part design refined before a working product was achieved (Atherton, 2013a), a product whose appearance and material structure are unlike any gun previously made. Secondly, the distributive power of the Internet means that a design that is sufficiently compelling to users will proliferate uncontrollably. Four days after Defense Distributed made the CAD files for the Liberator freely available, the US State Department requested the files were removed, citing possible violation of trade controls regarding the export of firearms (Preston 2013), yet by that time the files had been downloaded more than 100000 times (Atherton, 2013b). And finally, the four freedoms of open design mean that any design must be considered a prototype of a subsequent design which modifies it. Within open design, the notion of a 'finished' product is redundant. The original Liberator gun fired only one shot, requiring the barrel to be changed before it could be re-fired, leading critics to dismiss it as expensive and impractical. Less than two weeks later however, news emerged of a new version, produced using a 3D Printing technology (fused deposition modelling) much cheaper than the original laser sintered version, which was capable of firing eight shots (Greenberg, 2013). Furthermore, the new barrel incorporated rifling, enabling the design to comply with some regulations of the National Firearms Act, which govern improvised weapons.

\section{OPENED DESIGN}

Despite the precision of Katz's definition of open design, examples of NPD which do not fully embrace the four freedoms have nonetheless been described as open design. Tooze et al (2014) note that open design is "a catchall term for various... design and making activities", including those in which either contributions or solutions are not completely open. In 
particular, products which allow modification but which restrict distribution (for example) cannot be classed as open design under the strict conditions of Katz's definition. For this reason, Sinclair and Campbell (op. cit) introduce a new term, 'Opened Design', to describe products whose IP rights have been relaxed by the owner, but to a lesser degree than with open design. Typically these rights provide for the modification of an existing design and distribution of the resultant product, but with subsequent IP rights accruing to the original owner.

One designer who has been experimenting with opened design strategies for a number of years is Ronen Kadushin (though confusingly, Kadushin refers to his work as Open Design). First published in 2005, his Open Design manifesto celebrates the new opportunities presented by CAD files, CNC machining, and the power of the internet to distribute and share designs (Kadushin, 2010). The ability of interested users to modify, personalise and reimagine the original design is also fundamental to the work. Speaking of his Hack Chair design Kadushin (2011) explains:

"If you want to make it more comfortable, it's an open design. Go ahead, make it comfortable, add your nice round radiuses... I could have designed it to be straight and rounded and nice, but I chose not to... This is my choice; you have other choices, and you can have other points of view."

Visitors to Kadushin's website are able to download, for free, the designs for approximately 30 products, which are supplied as dxf files. These can be opened using 2D drawing software such as Adobe Illustrator, consumer-oriented 3D modelling software such as SketchUp, or professional level 3D CAD software such as Solidworks. Kadushin's designs therefore demand that the amateur designer possesses a certain level of expertise in the tools required for modification or re-design, in the same way that Wilson's Liberator does.

Also supplied with the dxf files are a set of instructions for how to make the product, including suggestions for material types and thicknesses (the majority of designs are intended to be laser cut, then hand-bent into shape). Kadushin thus satisfies freedoms 1 and 2 of Katz's definition above, and the ability to pass on the dxf files to others satisfies freedom 3. However a condition of sharing any new design is that it is redistributed under a Creative Commons 'Attribution-Non Commercial-Share Alike' (By-NC-SA) licence, which prohibits commercial uses. Kadushin is up-front about the reasons for this: "I am saying: 
please copy. But if you want to make a business out of it, then please call me and we'll discuss royalties. It is my intellectual property, after all" (Kadushin, 2011), and it may reasonably be argued that for a designer trying to make a living from their work, this is the most sensible option to take. Nonetheless, the By-NC-SA licence is one of the more restrictive Creative Commons licences, and does not satisfy the requirements for approval as a Free Cultural Work (Creative Commons, 2014). It also fails to fully satisfy the $4^{\text {th }}$ of Katz's freedoms, in that it places restrictions on the redistribution of modified designs. Kadushin's work therefore raises questions about the extent to which truly open design presents a viable option for those who wish to make a profession from design.

\section{WHAT WILL DESIGNERS DO WHEN EVERYONE CAN BE A DESIGNER?}

It is often tempting, when imagining the future, to predict that new technologies will displace and make redundant previously established ways of doing things. The reality is usually much more nuanced, with new technologies being used in different ways, many of them previously unpredicted, often alongside the old technologies they were supposed to usurp. To state that in future, digital fabrication will fundamentally change all industrial design practice, is likely to prove a reckless claim. Mass production technologies will continue to be best suited for products where identical, standardised, parts are required; this will include both 'low value' items such as packaging, but also high value items such as components which require extensive performance testing, which it might be unfeasible to undertake for individually designed parts. It is also likely that mass production and digital fabrication technologies will be combined to create hybrid production processes, utilising the particular advantages of each system. What may be more accurate to say therefore, is that in future the job of some designers will be very different to their job today. The opportunities which digital fabrication presents for the manufacture of items in low volume, perhaps in 10's or 100's of units, means that some designers will specialise in the design of niche products, for small markets, in the manner suggested by Aldersey Williams (op.cit). Others will design products requiring user inputs via toolkits enabled by 3D Printing and other digital fabrication technologies, using their expertise whilst making decisions about which elements of a product's design should be changeable and which should be constrained. 
Much of the discussion surrounding digital fabrication and its impact on the work that designers do has emphasised the expertise of the amateur, whether alone or as part of a crowd, and the opportunities which are presented by access to the means of production. As Anderson (op.cit.) writes:

"The tools of factory production, from electronics assembly to 3-D printing, are now available to individuals, in batches as small as a single unit. Anybody with an idea and a little expertise... can become a virtual micro-factory, able to design and sell goods without any infrastructure or even inventory."

This ability to act as designer and manufacturer, without the need to sell an idea to a company with the financial might to buy access to mass production technology, is crucial to an understanding of the future of design, and is fundamental to what makes that future different from the past. But what Anderson pays less attention to is the nature of the expertise required to engage with this future. In the four approaches to design outlined above, all require significant expertise in order for a beautiful, functioning object to result from the process. In only one of these, Open Design, is that expertise the sole domain of the user. In future Mass Customisation scenarios, professional expertise will continue to be required to imagine the object, to define the parameters of the solution space (Franke and Piller, 2004) such that function, safety, brand image, cost, etc. are reconciled with the user's designs. In addition a new type of design specialism will require the expertise to direct the user's interactions with the customisation toolkit such that the experience is one which they wish to repeat. In Crowdsourced NPD projects, professional expertise will be required for the same reasons, except the design of the customisation toolkit will be replaced with the design of the competition which users enter. Similarly professional expertise will again be required in Opened Design situations, where the design of the toolkit and the design of the competition will be replaced by the design of the instructions for modification and production. In all three situations the user will then apply their own expertise in modifying and finishing the design, ensuring the resulting product is one that best fits their requirements. Thus the future of design using these methods is one of collaboration between the expertise of the professional and amateur.

Mass Customisation, Crowdsourcing and Opened Design all, to varying extents, constrain the ability of the user to modify the original design. This allows brands and manufacturers to 
retain a degree of control over the manifestation of the design of products which users engage with. Yet these constraints also offer significant advantages to the consumer, by simplifying design and manufacturing tasks whilst at the same time setting limits on what such tasks can achieve. A consumer engaging with a brand that offers the ability to personalise its products will also benefit from assurances of safety, compliance with trade standards and consumer law, compatibility with other products where required, and, in some circumstances, a manufacturer's warranty. Such assurances may be worth little to the user whose knowledge of, and interest in, a particular product is sufficient to enable him/her to engage in Open Design. For a user with less time or expertise, who instead wants to personalise an existing product such that it better suits their requirements, design spaces which are less open will be more appropriate. It is therefore apparent that in many, and perhaps most, situations it will be the restraints placed on the user which enable them to engage in design.

Open Design is exceptional, in that it does not require the expertise of the professional designer. But this does not mean that that the expertise required of the designer is any less; rather it requires that the expertise of the amateur is equal to that of the professional. In the case of the Liberator gun, as Wilson points out, "These aren't the only gun files on the internet... there's CNC gun files all over... There are files out there to make metal gun components or various dangerous things" (Atherton, 2013b, op.cit.). However, in these instances, designing and manufacturing a working gun requires expertise and skill using numerous workshop tools and machines. In contrast, the user who downloaded files of the Liberator and printed them without making modifications would not be acting as a designer, instead they would be acting merely as a consumer of a product created as a result of an Open Design process. To re-design the gun in a way that made it cheaper and more reliable, as described above, required significant expertise both in the design and construction of guns, and the CAD software needed to modify the original part files.

The power of the Liberator as a means of drawing attention to the possibilities of Open Design undoubtedly lies in its ability - as a gun - to arouse strong passions. This in turn leads to interesting questions regarding the ethics of encouraging, or expecting, users to engage in design and personalisation. In 'Moralizing Technology', Verbeek (2011, p.64) considers the 
question of whether artifacts have morality, and concludes that moral agency lies in an assembly of the user and the object:

"A gun is not a mere instrument, a medium for the free will of human beings... the gun and the man form a new entity, and this entity does the shooting."

The composition of this new entity is particularly relevant to the consideration of expertise amongst those engaged in design. Many hobbyists use legally available parts to build guns, and books with titles such as 'Home Workshop Prototype Firearms' (Holmes, 1994) are available in both paperback and Kindle formats from Amazon. In Verbeek's construction of the gun and the man as a new entity, there is little difference between a 3D printed Liberator capable of firing a single shot, and a hand-crafted replica duelling pistol made by an expert amateur gunsmith. But what appears to have caused most concern amongst opponents of the Liberator project is not that it is legal for amateurs to make their own firearms, but rather that distribution of the CAD files might allow someone with little expertise to make a gun. Arguing from such a position, it appears the morality of the gunman entity is modified by the expertise of the person making the gun. This position - that workshop proficiency is a good indicator of suitability to own a gun - is somewhat peculiar. Yet in banning the distribution of the CAD files needed to manufacture the Liberator it is nontheless one that US legislators appear to endorse. The pervasiveness of such an idea, when applied to less contentious products than guns, may determine the speed at which a future of consumer-designers arrives.

When everyone can be a designer, there will not just be one future for designers, but a number of different ones. Some designers will work in ways which appear very similar to designers today, working to briefs set by clients to create products which are mass produced. Others will be employed by brands to design unfinished products which users will personalise in the knowledge that the final design will be safe and reliable, or which utilise digital fabrication technologies to enable niche products in low volume production runs. Designers employed by brands which engage in crowdsourcing will work in collaboration with users to bring products to production. And some people will practise design with a high degree of expertise, even though they may not be trained and it may not be their full time job. Perhaps the only certainty is that when the means of design and production are placed in the hands of users, they will use them in ways we cannot currently anticipate. 


\section{REFERENCES}

van Abel, B; Evers, L; Klaassen, R. and Troxler, P. (eds) (2011), Open Design Now, Amsterdam: BIS. Aldersey-Williams, H. (2011), The New Tin Ear: Manufacturing, Materials and the Rise of the UserMaker, London: RSA.

Anderson, C. (2010), In the Next Industrial Revolution, Atoms Are the New Bits, Wired, 18.01.

Atherton, K.D. (2013a), How The World's First 3-D Printed Gun Works, Popular Science [online], available from: http://www.popsci.com/technology/article/2013-05/worlds-first-fully-3-dprinted-gun-here [accessed 07.12.2014].

Atherton, K.D. (2013b), Defense Distributed's Cody Wilson On Being Told To Remove 3-D Printed Gun Plans: "We Win", Popular Science [online], available from:

http://www.popsci.com/technology/article/2013-05/defense-distributeds-cody-wilsontakedown-notice-we-win [accessed 07.12.2014].

Bernabei, R and Power, J. (2013), Designing together: end-user collaboration in designing a personalised product, in Proceedings of the 10th European Academy of Design Conference, 17-19 April, Gothenburg, Sweden.

Black, A. (2007), User-centred design [online], Design Council, available from: http://web.archive.org/web/20071021042720/http://www.design-council.org.uk/en/AboutDesign/Design-Techniques/User-centred-design-/ [accessed 07.12.2014].

Bonanni, L.A; Parkes, A.J. and Ishii, H. (2008), Future craft: how digital media is transforming product design, in Proceedings of the 2008 Conference on Human Factors in Computing Systems, CHI 2008, April 5-10, Florence, Italy.

Brabham, D, (2008), Crowdsourcing as a Model for Problem Solving: An Introduction and Cases, Convergence: The International Journal of Research into New Media Technologies, 14(1): pp. 7590.

Campbell, R.I.; Hague, R.; Sener, B. and Wormald, P. (2003), The potential for the bespoke industrial designer, The Design Journal, 6(3), pp.24-34

Caplan, R. (ed). (1969), Design in America: selected work by members of the Industrial Designers Society of America, New York: McGraw-Hill.

Creative Commons (2014), Understanding Free Cutural Works, [online], available from: http://creativecommons.org/freeworks [accessed 07.12.2014].

Davis, S. (1987), Future Perfect, Reading MA: Addison-Wesley.

Defense Distributed, (2014), DD History [online], available from: https://defdist.org/dd-history/ [accessed 07.12.2014].

Design Council, (2008), Ten ways you can profit from design, Design Council Magazine, Issue 5, Autumn 2008.

Design Council (2010), Introducing Product Design [online], available from: http://web.archive.org/web/20130827124810/http://www.designcouncil.org.uk/aboutdesign/Types-of-design/Product-design/Introducing-product-design/ [accessed 07.12.2014]. 
Dillow, C. (2012), Q+A: Cody Wilson Of The Wiki Weapon Project On The 3-D Printed Future of Firearms, Popular Science [online], available from:

http://www.popsci.com/technology/article/2012-12/qa-cody-wilson-wiki-weapons-project-3-dprinted-future-firearms [accessed 07.12.2014].

Duffy, J. and Keen, A. (2006), Can Anyone be a Designer? Fast Company, Issue 109, October 2006, p. 116.

Fiell, C. and Fiell, P. (2003), Industrial Design A-Z, Köln: Taschen.

Fischer, G. (2002), Beyond "Couch Potatoes": From Consumers to Designers and Active Contributors, First Monday, 7(12), available from: http://firstmonday.org/ojs/index.php/fm/article/view/1010/931 [accessed 07.12.2014]

Franke, N. and Piller, F. (2004), 'Value Creation by Toolkits for User Innovation and Design: The Case of the Watch Market', The Journal of Product Innovation Management, 21, pp. 401-415.

Franke, N; Schreier, M. and Kaiser, U. (2010), The "I Designed It Myself" Effect in Mass Customization, Management Science, 56(1), pp. 125-140.

Goodman-Deane, J.; Langdon, P. and Clarkson, J. (2010), Key influences on the user-centred design process, Journal of Engineering Design, 21(2-3), pp.345-373.

Greenberg, A. (2013), \$25 Gun Created With Cheap 3D Printer Fires Nine Shots (Video), Forbes [online], available from: http://www.forbes.com/sites/andygreenberg/2013/05/20/25-guncreated-with-cheap-3d-printer-fires-nine-shots-video/ [accessed 07.12.2014].

Hermans, G. and Stolterman, E. (2012), Exploring Parametric Design: Consumer Customization of an Everyday Object, in Leading Innovation through Design: Proceeding of the DMI 2012 International Research Conference, 1-4 July, Chulalongkorn University, Bangkok, Thailand.

von Hippel, E. and Katz, R. (2002), Shifting innovation to users via toolkits, Management Science, 48(7), pp. 821-833.

Holmes, B, (1994), Home Workshop Prototype Firearms: How to Design, Build and Sell Your Own Small Arms, Boulder, CO: Paladin Press.

Howe, J. (2006a), Crowdsourcing: A Definition [online], available from: http://www.crowdsourcing.com/cs/2006/06/crowdsourcing a.html [accessed 07.12.2014]

Howe, J. (2006b), The Rise of Crowdsourcing, Wired [online], available from: http://www.wired.com/wired/archive/14.06/crowds pr.html [accessed 07.12.2014].

Howe, J. (2009), Is Crowdsourcing Evil? The Design Community Weighs In, Wired [online], available from: http://www.wired.com/2009/03/is-crowdsourcin/ [accessed 07.12.2014].

IDSA (2010), Industrial Design: Defined [online], available from: http://www.idsa.org/what-isindustrial-design [accessed 07.12.2014].

Ive, J. (2009), Quoted in McGuirk, J. (2009), Fabbers, Dabblers and Microstars, Icon, Issue 73, 14.08.2009.

Kadushin, R. (2010), Open Design Manifesto [online], available from: http://www.ronenkadushin.com/files/4613/4530/1263/Open Design Manifesto-Ronen Kadushin .pdf [accessed 07.12.2014]. 
Kadushin, R. (2011), Quoted in Troxler, P. (2010), The Beginning of a Beginning of the Beginning of a Trend, in van Abel, B; Evers, L; Klaassen, R. and Troxler, P. (eds), Open Design Now, Amsterdam: BIS.

Kaplan, A. and Hänlein, M. (2006), Towards a Parsimonious Definition of traditional and Electronic Mass Customization, Journal of Product Innovation Management, 23(2), pp.168-182.

Katz, A. (2011), Authors and Owners, in van Abel, B; Evers, L; Klaassen, R. and Troxler, P. (eds), Open Design Now, Amsterdam: BIS.

Kleeman, F; Voß, G.G. and Rieder, K. (2008), Un(der)paid Innovators: The Commercial Utilization of Consumer Work Through Crowdsourcing, Science, Technology and Innovation Studies, 4(1), pp. 526.

Mansour, S. and Hague, R. (2003), Impact of Rapid Manufacturing on Design for Manufacture for Injection Moulding, in Proceedings of the Institute of Mechanical Engineers, Part B, Journal of Mechanical Engineering Science, 217(4), pp.453-461.

McDermott, C. (2007), Design: The Key Concepts, London: Routledge.

Merchant, N. (2013), Onlyness: Nilofer Merchant at TEDxHouston 2012, [online], available at https://www.youtube.com/watch?v=h-8MXo-tJoQ, [accessed 08.12.2014].

McGuirk, J. (2009), Fabbers, Dabblers and Microstars, Icon, Issue 73, 14.08.2009.

Mugge, R; Schoormans, J.P.L. and Hendrik, N.J. (2009), Emotional bonding with personalised products, Journal of Engineering Design, 20(5), pp. 467-476.

Norman, D. (2004), Emotional Design, New York: Basic Books.

Oudshoorn, N. and Pinch, T. (2003), How Users and Non-Users Matter, in Oudshoorn, N. and Pinch, T. (eds), How Users Matter, Cambridge, MA: MIT Press.

Perks, H; Cooper, R. and Jones, C. (2005), Characterizing the Role of Design in New Product Development: An Empirically Derived Taxonomy, Journal of Product Innovation Management, 22(2), pp. 111-127.

Piller, F. (2005), Mass Customization: Reflections on the State of the concept, International Journal of Flexible Manufacturing Systems, 16(4), pp. 313-334.

Pine II, J. (1993), Mass Customization: The New Frontier in Business Competition, Boston: Harvard Business School Press.

Postigo, H. (2003), From Pong to Planet Quake: Post-Industrial Transitions from Leisure to Work, Information, Communication \& Society, 6(4), pp. 593-607.

Preston, J. (2013), Printable-Gun Instructions Spread Online After State Dept. Orders Their Removal, New York Times, May 10th 2013.

Raasch, C; Herstatt, C. and Balka, K. (2009), On the open design of tangible goods, R\&D Management, 39(4), pp. 382-393.

Rahim, A. (2009), Uniformity and Variability in Architectural Practice in Spuybroek, L. (ed), The Architecture of Variation, London: Thames and Hudson. 
Randall, T; Terwiesch, C. and Ulrich, K. (2003), Principles for User Design of Customized Products, California Management Review, 47(4), pp. 68-85.

Redström, J. (2008), 'RE:Definitions of use', Design Studies, 29(4), pp. 410-423.

Risatti, H. (2006), Craft vs. Design / Recognition vs. Understanding, Metalsmith, 26(2), pp. 14-17.

Rogers, J. (2010), Can a community design a car? The Do Lectures [online], available from: http://www.thedolectures.com/jay-rogers-can-a-community-design-a-car\#.VIHS6zGsV8E [accessed 07.12.2014].

Sanders, E.B-N and Stappers, P.J. (2008), Co-Creation and the New Landscapes of Design, CoDesign, 4(1), pp. 5-18.

Sinclair, M. and Campbell, R.I. (2014), A Classification of Consumer Involvement in New Product Development, in Proceedings of DRS 2014. Design's Big Debates: Pushing the Boundaries of Design Research, 16th-19th June 2014, Umeå University, Sweden, pp. 1582-1598.

Steen, M. (2011), Tensions in human-centred design, CoDesign, 7(1), pp.45-60.

Tonkinwise, C. (2004), Is design finished? Dematerialisation and changing things, in Willis, A.M. (ed), Design Philosophy Papers, collection two, Ravensbourne, Australia: Team D/E/S Publications.

Tooze, J; Baurley, S; Phillips, R; Smith, P; Foote, E. and Silve, S. (2014), Open Design: Contributions, Solutions, Processes and Projects, The Design Journal, 17(4), pp. 538-559.

Ulrich, K. and Eppinger, S. (1995), Product design and development, 5th Ed. New York: McGraw-Hill.

Ulwick, A.W. (2002), Turn consumer input into innovation, Harvard Business Review, January, pp. 9297.

Verbeek, P-P. (2011), Moralizing Technology: Understanding and Designing the Morality of Things, Chicago: The University of Chicago Press

Vredenburg, K; Mao, J-Y; Smith, P.W. and Carey, T. (2002), A Survey of User-Centered Design Practice, in Proceedings of the SIGCHI Conference on Human Factors in Computing Systems (CHI '02), ACM, New York.

Walker, J. (1989), Design History and the History of Design, Eastbourne, UK: Pluto.

Wong, D. (2010), NikeID Makes $\$ 100 \mathrm{M}+$ : Co-Creation Isn't Just a Trend, Huffington Post [online], available from: http://www.huffingtonpost.com/danny-wong/nikeid-makes-100m-cocrea b 652214.html [accessed 07.12.2014]. 